\title{
THERMOCHEMICAL PROPERTIES OF
}

\section{4- $N, N$-DIALKYLAMINO-7-NITROBENZOFURAZAN DERIVATIVES (ALKYL $=$ METHYL, ETHYL)}

Ana Filipa L. O. M. Santos, ${ }^{\phi}$ Ana L. R. Silva, ${ }^{\phi}$ Otília D. F. Santiago, ${ }^{\phi}$ Jorge M.

Gonçalves, ${ }^{\phi * *}$ Siddharth Pandey, ${ }^{* *}$ W. E Acree Jr., Maria D. M. C. Ribeiro da Silva ${ }^{\phi}$

${ }^{\phi}$ Centro de Investigação em Química, Department of Chemistry and Biochemistry, Faculty of Science, University of Porto, Rua do Campo Alegre, 687, P-4169-007, Portugal

•Department of Chemistry, University of North Texas, Denton, Texas 76203 (USA)

*Present address

Department of Chemistry, Indian Institute of Technology Delhi, Hauz Khas, New Delhi, 110016 (India)

** Corresponding author:

e-mail address: jmgoncalves@fc.up.pt;

fax: +351 220402 659; phone: + 351220402534 


\begin{abstract}
The standard $\left(p^{\circ}=0.1 \mathrm{MPa}\right)$ molar enthalpies of formation, at $T=298.15 \mathrm{~K}$, in the gaseous phase, for two nitrobenzofurazan derivatives, 4- $N, N$-dimethylamino-7nitrobenzofurazan (DMANBF) and 4- $N, N$-Diethylamino-7-nitrobenzofurazan (DEANBF), were derived from their enthalpies of combustion and sublimation, obtained by static bomb calorimetry and by the Knudsen effusion technique, respectively. The results are compared with the corresponding data calculated by the G3(MP2)//B3LYP approach. Computationally, the molecular structures of both compounds were established and the geometrical parameters were determined at the B3LYP/6-31G(d) level of theory.
\end{abstract}

KEYWORDS: Enthalpy of combustion; Enthalpy of sublimation; Enthalpy of formation; Combustion calorimetry; Knudsen effusion; G3(MP2)//B3LYP calculations; 4- $N, N$-dimethylamino-7-nitrobenzofurazan; 4- $N, N$-diethylamino-7-nitrobenzofurazan. 


\section{Introduction}

During the last two decades, our Research Group has been involved in a systematic study of the dissociation enthalpy of terminal $\mathrm{N}-\mathrm{O}$ bonds in heterocyclic compounds [112]. These studies are a contribution to the understanding of the chemical behavior of those organic compounds, particularly as oxidizing agents, enabling the ordering of them on a reactivity scale [1]. Several classes of compounds with $\mathrm{N}-\mathrm{O}$ terminal bonds have been studied, with particular attention devoted to quinoxaline $N, N$-dioxides [2-7], pyrazine $N, N$-dioxides [1,8,9], phenazine $N, N$-dioxides [10], benzofurazan $N$-oxides [1], pyridine $N$-oxides [11] and dipyridil $N$-oxides [12]. We have extended recently these studies to 4-nitro-2,1,3-benzothiadiazoles [13] and Miranda et al. also have published studies on the structure, energetics and aromaticity of 2,1,3-benzothiadiazole [14,15]. In this context, we report herein a new contribution for the energetic characterization of two nitrobenzofurazan derivatives, namely 4- $N, N$-dimethylamino-7-nitrobenzofurazan (DMANBF) and 4-N,N-diethylamino-7-nitrobenzofurazan (DEANBF), whose structural formula are represented in figure 1.

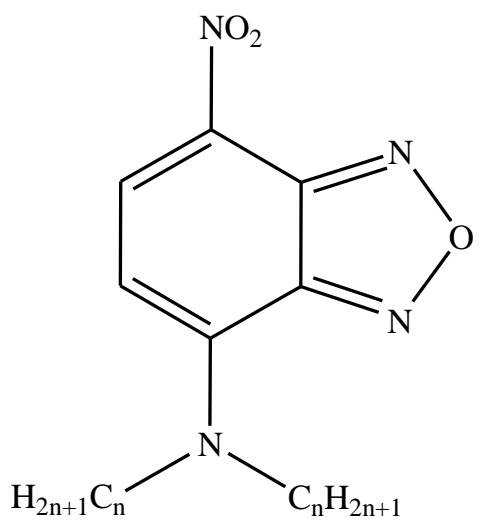

FIGURE 1. Structural formula of 4-N,N-dimethylamino-7nitrobenzofurazan (DMANBF, $\mathrm{n}=1$ ) and of 4- $N, N$-diethylamino-7nitrobenzofurazan (DEANBF, $\mathrm{n}=2$ ).

The enthalpies of formation of these two crystalline compounds and their enthalpies of sublimation, at $T=298.15 \mathrm{~K}$, have been derived from static bomb calorimetry and from Knudsen effusion method, respectively. From these results, the standard $\left(p^{\circ}=0.1\right.$ $\mathrm{MPa}$ ) molar enthalpies of formation, in the gaseous phase, at $T=298.15 \mathrm{~K}$, were derived, and were compared with estimated data, calculated by the G3(MP2)//B3LYP approach. 
Computationally, the molecular structures of both compounds were established and the geometrical parameters were determined at the B3LYP/6-31G(d) level of theory.

\section{Experimental}

\subsection{Synthesis and characterization of compounds}

4- $N, N$-Dimethylamino-7-nitrobenzofurazan (DMANBF; CAS 1455-87-4) was prepared by a published literature method $[16,17]$. The synthetic procedure involved treating an ethanolic solution of 4-chloro-7-nitrobenzofurazan with aqueous dimethylamine (40\% by mass). The crude product was collected by filtration under reduced pressure, and was further purified by two crystallizations from propanone. 4- $N, N$-Diethylamino-7-nitrobenzofurazan (DEANBF; CAS 74392-01-1) was prepared in similar fashion using an aqueous diethylamine solution.

Elemental analysis were in agreement with expected values. The compositions in mass fractions $\mathrm{w}$ of $\mathrm{C}, \mathrm{H}$, and $\mathrm{N}$ are presented in Table 1 .

Table 1

Synthesis details and analysis details of the samples studied

\begin{tabular}{|l|l|l|l|}
\hline Chemical Name & CAS No. & $\begin{array}{l}\text { Synthetic } \\
\text { Procedure } \\
\text { Reference }\end{array}$ & Elemental Analysis \\
\hline $\begin{array}{l}4-N, N \text {-Dimethylamino-7- } \\
\text { nitrobenzofurazan }\end{array}$ & $1455-87-4$ & {$[16,17]$} & $\begin{array}{l}\text { found: } w(C), 0.4623 ; \mathrm{w}(\mathrm{H}), 0.0391 ; \\
\mathrm{w}(\mathrm{N}), 0.2684 ; \text { calculated: } \mathrm{w}(\mathrm{C}), \\
0.4616 ; \mathrm{w}(\mathrm{H}), 0.0387 ; \mathrm{w}(\mathrm{N}), 0.2691\end{array}$ \\
\hline $\begin{array}{l}4-N, N \text {-Diethylamino-7- } \\
\text { nitrobenzofurazan }\end{array}$ & $74392-01-1$ & {$[16,17]$} & $\begin{array}{l}\text { found: } \mathrm{w}(\mathrm{C}), 0.5079 ; \mathrm{w}(\mathrm{H}), 0.0519 ; \\
\mathrm{w}(\mathrm{N}), 0.2370 ; \text { calculated: } \mathrm{w}(\mathrm{C}), \\
0.5084 ; \mathrm{w}(\mathrm{H}), 0.0512 ; \mathrm{w}(\mathrm{N}), 0.2372\end{array}$ \\
\hline
\end{tabular}

Both compounds were submitted to further purification before their thermochemical studies, being recrystallized from water-ethanol mixture (1:1). The final purity of the compounds was confirmed recovering the carbon dioxide produced in the combustion experiments. The compound 4- $N, N$-dimethylamino-7-nitrobenzofurazan absorbed a small amount of moisture, as shown by the $\mathrm{CO}_{2}$ average ratio value, lower than 0.999 mass fraction. The presence of water was confirmed by FT-IR studies (spectrum BX FT-IR, Perkin-Elmer spectrometer). The average ratios of the mass of carbon dioxide recovered after combustion experiments to that calculated from the mass of sample for 4- $N, N$-diethylamino-7-nitrobenzofurazan was $(0.9990 \pm 0.0006)$ (value in mass fraction). 


\subsection{Combustion calorimetry}

The standard $\left(p^{\circ}=0.1 \mathrm{MPa}\right)$ massic energies of combustion for the two compounds were measured using a static-bomb combustion calorimeter, originally constructed at the National Physical Laboratory (Teddington, Middlesex, UK) [18]. This is an isoperibol calorimeter equipped with a twin valve bomb (internal volume: $0.290 \mathrm{dm}^{3}$ ) whose detailed description and procedure is reported in literature [19]. The calorimetric system was calibrated using benzoic acid (BAS-CRM 190p) having a massic energy of combustion, under standard bomb conditions, of $-(26431.8 \pm 3.7) \mathrm{J} \cdot \mathrm{g}^{-1}$. The calibration experiments were made in an oxygen atmosphere at $p=3.04 \mathrm{MPa}$, with $1.00 \mathrm{~cm}^{3}$ of deionized water added to the bomb, leading to an energy equivalent value for the calorimeter of $\varepsilon_{\text {cal }}=(15543.3 \pm 0.6) \mathrm{J} \cdot \mathrm{K}^{-1}$, where the uncertainty quoted is the standard deviation of the mean. The calibration results were corrected to an energy equivalent, $\mathcal{E}_{\mathrm{cal}}$, corresponding to an average mass of water added to the calorimeter of $2900.0 \mathrm{~g}$.

The samples of the compounds, in the pellet form, were ignited at $T=298.15 \mathrm{~K}$, in an oxygen atmosphere $(p=3.04 \mathrm{MPa})$, with $1.00 \mathrm{~cm}^{3}$ of deionized water added to the bomb. $n$-hexadecane (Aldrich, Gold Label), with a massic energy of combustion of $\Delta_{\mathrm{c}} u^{\circ}=-(47164.3 \pm 3.6) \mathrm{J} \cdot \mathrm{g}^{-1}$, was used as auxiliary of combustion to end the incomplete combustions and to produce an appropriate temperature rise. For the cotton thread fuse (empirical formula $\mathrm{CH}_{1.686} \mathrm{O}_{0.843}$ ), $\Delta_{\mathrm{c}} u^{\circ}=-16240 \mathrm{~J} \cdot \mathrm{g}^{-1}$ [20]. The values of the massic energies of combustion of $n$-hexadecane and of cotton have been previously confirmed by combustion in our laboratory.

The electric energy for ignition was determined from the change in potential difference on discharge of a $1400 \mu \mathrm{F}$ condenser across a platinum wire. The corrections for nitric acid formation were based on $-59.7 \mathrm{~kJ} \cdot \mathrm{mol}^{-1}$ [21], for the molar energy of formation of $0.1 \mathrm{~mol} \cdot \mathrm{dm}^{-3} \mathrm{HNO}_{3}(\mathrm{aq})$ solution from $\mathrm{N}_{2}(\mathrm{~g}), \mathrm{O}_{2}(\mathrm{~g})$ and $\mathrm{H}_{2} \mathrm{O}$ (l). The value for the pressure coefficient of specific energy $(\partial u / \partial p)_{\mathrm{T}}=-0.2 \mathrm{~J} \cdot \mathrm{g}^{-1} \cdot \mathrm{MPa}^{-1}$ at $T$ $=298.15 \mathrm{~K}$, a typical value for organic compounds, was assumed [22]. The amount of the compound burnt in each experiment was determined from the total mass of carbon dioxide produced, taking into account that formed from the combustion of the cotton thread fuse and from $n$-hexadecane. For these compounds, the standard massic energy 
of combustion, $\Delta_{\mathrm{c}} u^{\circ}$, was calculated by a similar procedure to that developed by Hubbard et al. [23].

\subsection{Enthalpies of sublimation using a quartz crystal deposition system}

The standard enthalpy of sublimation of the two compounds were derived by the Knudsen effusion method, using the quartz microbalance previously described [24,25]. The equipment was tested with several compounds of known standard molar enthalpies of sublimation (benzanthrone, squaric acid, and 4-hydroxy-2-methylquinoline) and good agreement was obtained [25,26]. The vapour effusing from the Knudsen cell was allowed to condense on a quartz crystal positioned above the effusion hole. For small masses, changes in the frequency of oscillation of the quartz crystal, $\Delta f$, were proportional to the mass condensed in its surface [27], $\Delta f=C_{\mathrm{f}} \Delta m$, where $C_{\mathrm{f}}$ is a proportionally constant. The vapour pressure can be derived using the Knudsen formula

$$
p=(\Delta m / \Delta t) a^{-1}(2 \pi R T / M)^{1 / 2}
$$

where $(\Delta m / \Delta t)$ is the rate of mass loss, $a$ is the effective hole area, and $M$ is the molar mass of the effusing vapour. As the measured rate of change of frequency of oscillation with time $v=\Delta f / \Delta t$ is directly proportional to the rate of sublimation of the crystalline sample [27], $v=C_{\mathrm{f}} \Delta m / \Delta t$ and

$$
p=\frac{v \cdot T^{1 / 2} \cdot(2 \pi R / M)^{1 / 2}}{a \cdot C_{\mathrm{f}}}
$$

The enthalpy of sublimation, $\Delta_{\mathrm{cr}}^{\mathrm{g}} H_{\mathrm{m}}^{\mathrm{o}}$, may be derived from the slope of $\ln \left(v T^{1 / 2}\right)$ against $T^{-1}$ by applying the integrated form of the Clausius-Clapeyron equation. From at least five independent sets of experimental measurements of the frequency of the quartz oscillator at convenient temperature intervals, it was possible to obtain five independent results for the enthalpy of sublimation of the compound, each one referred to the mean of the temperature range used.

\section{Computational thermochemistry}


The standard ab initio molecular orbital calculations for the 4- $\mathrm{N}, \mathrm{N}$-dimethylamino7-nitrobenzofurazan and 4- $\mathrm{N}, \mathrm{N}$-diethylamino-7-nitrobenzofurazan were performed with Gaussian 03 computer code [28], and the composite G3(MP2)//B3LYP approach was the methodology employed [29]. In this method, the geometry full-optimization and calculation of the frequencies of the molecule are done through the hybrid B3LYP method together with the split-valence polarized $6-31 \mathrm{G}(\mathrm{d})$ basis set. The zero-point energies (ZPEs) are obtained from B3LYP/6-31G(d) calculations, with a scale factor of 0.96. Then, single-point calculations are carried out at higher levels of electronic structure theory: quadratic configuration interaction (QCISD(T)) and the 2nd-order Moller-Plesset (MP2) with, respectively, the 6-31G(d) and GTMP2Large basis set.

The absolute enthalpies, at $T=298.15 \mathrm{~K}$, were obtained by adding the energies computed at $T=0 \mathrm{~K}$ with the vibrational, translational, rotational and the $p V$ terms computed at the B3LYP/6-31G(d) level of theory. These enthalpies, at $T=298.15 \mathrm{~K}$, were then used to estimate the enthalpy of formation of the compounds studied experimentally, by combining the enthalpy of the gas-phase working reactions (3)-(7) (for 4-N,N-dimethylamino-7-nitrobenzofurazan, $\mathrm{n}=1$ and for 4- $N, N$-diethylamino-7nitrobenzofurazan, $n=2$ ) and the experimental enthalpies of formation of the molecules there involved.

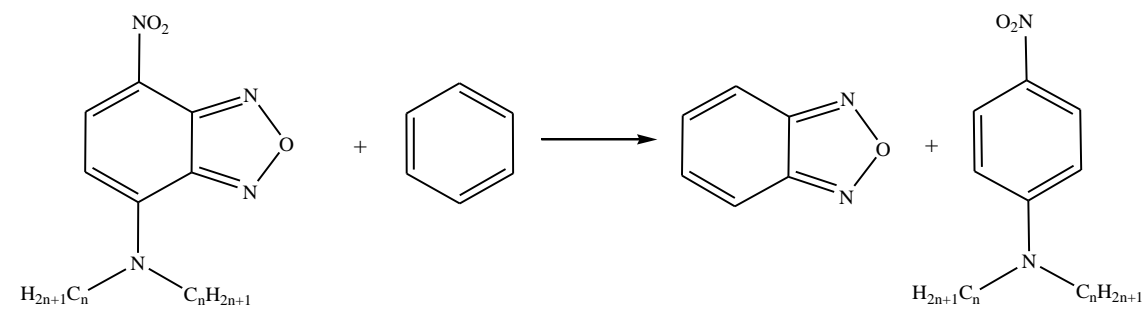

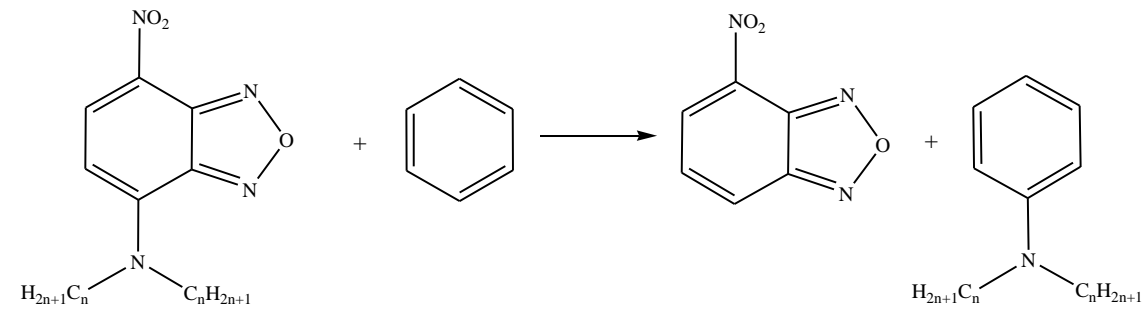<smiles>CCCCN(C)c1ccc(N)c2nonc12</smiles><smiles>O=[N+]([O-])c1cccc2n[nH]nc12</smiles> 


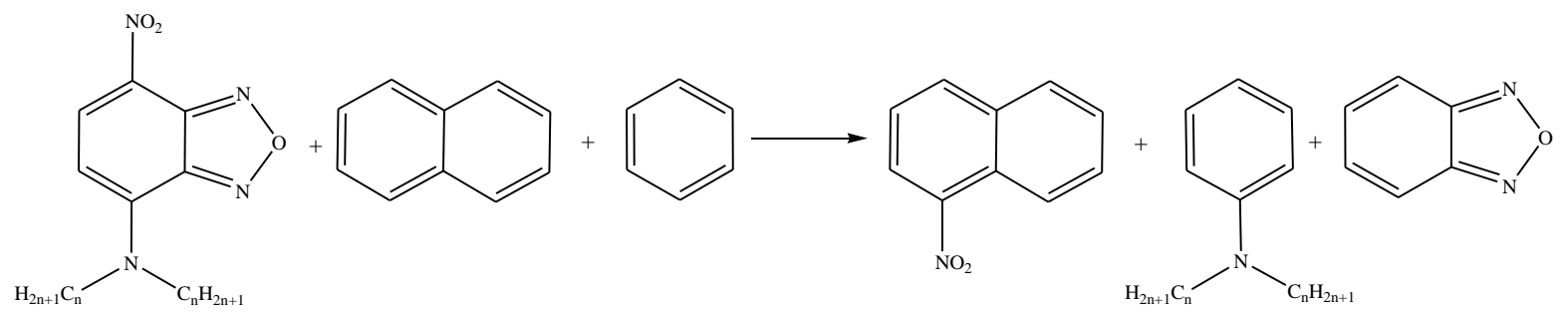

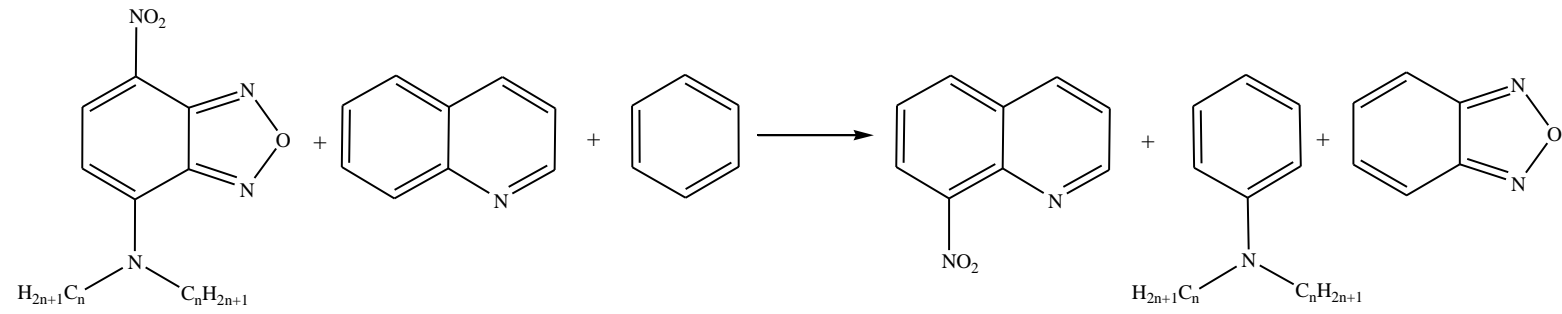

\section{Results and discussion}

\subsection{Experimental condensed phase and phase transition}

Results of a typical experiment for each compound are presented in table 2; $\Delta m\left(\mathrm{H}_{2} \mathrm{O}\right)$ is the deviation of the mass of water added to the calorimeter from $2900.0 \mathrm{~g}$; $\Delta U_{\Sigma}$ is the energy correction to the standard state; $\Delta U(\mathrm{IBP})$ is the internal energy for the isothermal bomb process calculated according to equation (8). The remaining terms have been previously described [23].

$$
\Delta U(\mathrm{IBP})=-\left\{\varepsilon_{\mathrm{cal}}+C_{p}\left(\mathrm{H}_{2} \mathrm{O}, \mathrm{l}\right) \cdot \Delta m\left(\mathrm{H}_{2} \mathrm{O}\right)+\varepsilon_{\mathrm{f}}\right\} \Delta T_{\mathrm{ad}}+\Delta U(\text { ign })
$$

TABLE 2

Typical combustion experiments at $T=298.15 \mathrm{~K}$

\begin{tabular}{lcc}
\hline & DMANBF & DEANBF \\
\hline$m\left(\mathrm{CO}_{2}\right.$, total $) / \mathrm{g}$ & 1.74819 & 1.63728 \\
$m($ cpd $) / \mathrm{g}$ & 0.63972 & 0.44253 \\
$m($ fuse $) / \mathrm{g}$ & 0.00428 & 0.00454 \\
$m(n-\mathrm{hex}.) / \mathrm{g}$ & 0.21203 & 0.25903 \\
$\Delta T_{\text {ad }} / \mathrm{K}$ & 1.53495 & 1.49094 \\
$\mathcal{f}_{\mathrm{f}} / \mathrm{J} \cdot \mathrm{K}^{-1}$ & 16.14 & 16.73 \\
$\Delta m\left(\mathrm{H}_{2} \mathrm{O}\right) / \mathrm{g}$ & 0.0 & -3.2 \\
$-\Delta U(\mathrm{IPB}) / \mathrm{J}$ & 23881.78 & 23179.10 \\
$\Delta U(\mathrm{HNO}) / \mathrm{J}$ & 75.84 & 41.43 \\
$\Delta U($ ign $) / \mathrm{J}$ & 1.19 & 1.16 \\
$\Delta U_{\Sigma} / \mathrm{J}$ & 15.46 & 11.62 \\
$\Delta U($ fuse $) / \mathrm{J}$ & 69.51 & 73.73 \\
$\Delta U(n-\mathrm{hex}) / \mathrm{J}$ & 10000.37 & 12217.01 \\
$-\Delta_{\mathrm{c}} u^{\circ} / \mathrm{J} \cdot \mathrm{g}^{-1}$ & 21447.82 & 24482.29 \\
\hline
\end{tabular}


$m\left(\mathrm{CO}_{2}\right.$, total $)$ is the total mass of $\mathrm{CO}_{2}$ recovered in the experiment; $m(\mathrm{cpd})$ is the mass of compound burnt in each experiment; $m$ (fuse) is the mass of fuse (cotton) used in each experiment; $m$ (n-hex.) is the mass of $n$-hexadecane burnt in the experiment; $\Delta T_{\text {ad }}$ is the corrected temperature rise; $\varepsilon_{\mathrm{f}}$ is the energy equivalent of contents in the final state; $\Delta m\left(\mathrm{H}_{2} \mathrm{O}\right)$ is the deviation of the mass of water added to the calorimeter from $2900.0 \mathrm{~g} ; \Delta U$ (IBP) is the energy change for the isothermal combustion reaction under actual bomb conditions and includes $\Delta U(\mathrm{ign}) ; \Delta U\left(\mathrm{HNO}_{3}\right)$ is the energy correction for the nitric acid formation; $\Delta U$ (ign) is the electrical energy for ignition; $\Delta U_{\Sigma}$ is the standard state correction; $\Delta U$ (fuse) is the energy of combustion of the fuse (cotton); $\Delta U(n$-hex.) is the energy of combustion of $n$-hexadecane; $\Delta_{\mathrm{c}} u^{\circ}$ is the standard massic energy of combustion.

The standard massic energies of combustion, $\Delta_{\mathrm{c}} u^{\circ}$, for $4-N, N$-dimethylamino-7nitrobenzofurazan and 4-N,N-diethylamino-7-nitrobenzofurazan, refer to the combustion reactions (9) and (10), respectively.

$$
\begin{aligned}
& \mathrm{C}_{8} \mathrm{H}_{8} \mathrm{~N}_{4} \mathrm{O}_{3}(\mathrm{cr})+17 / 2 \mathrm{O}_{2}(\mathrm{~g}) \rightarrow 8 \mathrm{CO}_{2}(\mathrm{~g})+4 \mathrm{H}_{2} \mathrm{O}(\mathrm{l})+2 \mathrm{~N}_{2}(\mathrm{~g}) \\
& \mathrm{C}_{10} \mathrm{H}_{12} \mathrm{~N}_{4} \mathrm{O}_{3}(\mathrm{cr})+23 / 2 \mathrm{O}_{2}(\mathrm{~g}) \rightarrow 10 \mathrm{CO}_{2}(\mathrm{~g})+6 \mathrm{H}_{2} \mathrm{O}(\mathrm{l})+2 \mathrm{~N}_{2}(\mathrm{~g})
\end{aligned}
$$

Detailed results of each combustion experiment, for 4- $N, N$-dimethylamino-7nitrobenzofurazan and 4-N,N-diethylamino-7-nitrobenzofurazan, are presented in tables S1 and S2, respectively, of the supplementary information.

The results of all combustion experiments, with the mean values, $\left\langle\Delta_{\mathrm{c}} u^{\circ}\right\rangle$, and their standard deviation, are given in table 3 . The derived standard molar energies, $\Delta_{\mathrm{c}} U_{\mathrm{m}}^{\circ}(\mathrm{cr})$, and enthalpies of combustion, $\Delta_{\mathrm{c}} H_{\mathrm{m}}^{\circ}(\mathrm{cr})$, and the standard molar enthalpies of formation, in the liquid phase, $\Delta_{\mathrm{f}} H_{\mathrm{m}}^{\circ}(\mathrm{cr})$, for each compound, at $T=298.15 \mathrm{~K}$, are given in table 4. The uncertainties associated to the standard molar energy and enthalpy of combustion are twice the overall standard deviation of the mean and include the uncertainties in calibration with benzoic acid and in the energy of combustion of $n$ hexadecane, used as combustion auxiliary [30,31]. To derive $\Delta_{\mathrm{f}} H_{\mathrm{m}}^{\circ}(\mathrm{cr})$ from $\Delta_{\mathrm{c}} H_{\mathrm{m}}^{\circ}(\mathrm{cr})$, the standard molar enthalpies of formation, at $T=298.15 \mathrm{~K}$, were used for $\mathrm{H}_{2} \mathrm{O}(\mathrm{l})$, $-(285.830 \pm 0.040) \mathrm{kJ} \cdot \mathrm{mol}^{-1}[32]$ and $\mathrm{CO}_{2}(\mathrm{~g}),-(393.51 \pm 0.13) \mathrm{kJ} \cdot \mathrm{mol}^{-1}[32]$.

\section{TABLE 3}

Individual values of the standard $\left(p^{\circ}=0.1 \mathrm{MPa}\right)$ massic energy of combustion, of the compounds, at $T=298.15 \mathrm{~K}$

\begin{tabular}{lc}
\hline DMANBF & DEANBF \\
\hline$-\Delta_{\mathrm{c}} u^{\circ} / \mathrm{J} \cdot \mathrm{g}^{-1}$ & \\
21447.82 & 24448.25 \\
21461.38 & 24502.57 \\
21467.58 & 24455.44 \\
21445.63 & 24504.20
\end{tabular}




\section{TABLE 4}

Standard $\left(p^{\circ}=0.1 \mathrm{MPa}\right)$ molar energies of combustion, $\Delta_{\mathrm{c}} U_{\mathrm{m}}^{\circ}$, standard molar enthalpies of combustion, $\Delta_{\mathrm{c}} H_{\mathrm{m}}^{\circ}$, and standard molar enthalpies of formation, $\Delta_{\mathrm{f}} H_{\mathrm{m}}^{\circ}$, for the compounds studied at $T=298.15 \mathrm{~K}$.

\begin{tabular}{lccc}
\hline Compound & $-\Delta_{\mathrm{c}} U_{\mathrm{m}}^{\circ}(\mathrm{cr}) /\left(\mathrm{kJ} \cdot \mathrm{mol}^{-1}\right)$ & $-\Delta_{\mathrm{c}} H_{\mathrm{m}}^{\circ}(\mathrm{cr}) /\left(\mathrm{kJ} \cdot \mathrm{mol}^{-1}\right)$ & $\Delta_{\mathrm{f}} H_{\mathrm{m}}^{\circ}(\mathrm{cr}) /\left(\mathrm{kJ} \cdot \mathrm{mol}^{-1}\right)$ \\
\hline DMANBF & $4464.1 \pm 3.1$ & $4460.4 \pm 3.1$ & $169.0 \pm 3.3$ \\
DEANBF & $5784.1 \pm 4.7$ & $5782.9 \pm 4.7$ & $132.8 \pm 4.9$ \\
\hline
\end{tabular}

The results of the sublimation experiments are summarized in tables 5 and 6 , where the mean temperature of the experimental range $\langle T\rangle$, the standard molar enthalpy of sublimation at $\left\langle T>, \Delta_{\mathrm{cr}}^{\mathrm{g}} H_{\mathrm{m}}^{\mathrm{o}}(<T>)\right.$, as well as the corresponding parameters $a$ and $b$ of the Clausius-Clapeyron equation, obtained using a least square fitting of the experimental data, are given. Each value of $\Delta_{\mathrm{cr}}^{\mathrm{g}} H_{\mathrm{m}}^{\mathrm{o}}(<T>)$ was corrected to $T=298.15 \mathrm{~K}$ using $\Delta_{\mathrm{cr}}^{\mathrm{g}} C_{p, \mathrm{~m}}^{\mathrm{o}}=-50 \mathrm{~J} \cdot \mathrm{K}^{-1} \cdot \mathrm{mol}^{-1}[24]$, to yield the value of the standard molar enthalpy of sublimation at $T=298.15 \mathrm{~K}$. The uncertainties assigned are twice the overall standard deviation of the mean.

\section{TABLE 5}

Values of enthalpies of sublimation of 4-N,N-dimethylamino-7-nitrobenzofurazan obtained for different temperature ranges; $a$ and $b$ are from the Clausius-Clapeyron equation, $\ln \left(v T^{1 / 2} / \mathrm{s}^{-2} \mathrm{~K}^{1 / 2}\right)=a-b \cdot(\mathrm{K} /$ $T)$, with $\left.b=\Delta_{\mathrm{cr}}^{\mathrm{g}} H_{\mathrm{m}}^{\mathrm{o}}(<T\rangle\right) / R ; R=8.3145 \mathrm{~J} \cdot \mathrm{K}^{-1} \cdot \mathrm{mol}^{-1}$

\begin{tabular}{|c|c|c|c|c|c|}
\hline Series & $\langle T\rangle / \mathrm{K}$ & $a$ & $B$ & $\frac{\Delta_{\mathrm{cr}}^{\mathrm{g}} H_{\mathrm{m}}^{\mathrm{o}}(<T>)}{\mathrm{kJ} \cdot \mathrm{mol}^{-1}}$ & $\frac{\Delta_{\mathrm{cr}}^{\mathrm{g}} H_{\mathrm{m}}^{\mathrm{o}}(T=298.15 \mathrm{~K})}{\mathrm{kJ} \cdot \mathrm{mol}^{-1}}$ \\
\hline A & 388.8 & $40.17 \pm 0.63$ & $15342 \pm 244$ & 127.56 & 132.1 \\
\hline B & 388.8 & $40.35 \pm 1.18$ & $15212 \pm 460$ & 126.48 & 131.0 \\
\hline $\mathrm{C}$ & 383.8 & $40.61 \pm 0.37$ & $15442 \pm 144$ & 128.39 & 132.7 \\
\hline $\mathrm{D}$ & 387.7 & $40.76 \pm 0.25$ & $15613 \pm 97$ & 129.81 & 134.3 \\
\hline
\end{tabular}




$$
<\Delta_{\mathrm{cr}}^{\mathrm{g}} H_{\mathrm{m}}^{\mathrm{o}}(T=298.15 \mathrm{~K})>=(134.2 \pm 3.4) \mathrm{kJ} \cdot \mathrm{mol}^{-1}
$$

\section{TABLE 6}

Values of enthalpies of sublimation of 4-N,N-diethylamino-7-nitrobenzofurazan obtained for different temperature ranges; $a$ and $b$ are from the Clausius-Clapeyron equation, $\ln \left(v T^{1 / 2} / \mathrm{s}^{-2} \mathrm{~K}^{1 / 2}\right)=a-b \cdot(\mathrm{K} /$ $T)$, with $b=\Delta_{\mathrm{cr}}^{\mathrm{g}} H_{\mathrm{m}}^{\mathrm{o}}(<T>) / R ; R=8.3145 \mathrm{~J} \cdot \mathrm{K}^{-1} \cdot \mathrm{mol}^{-1}$

\begin{tabular}{|c|c|c|c|c|c|}
\hline Series & $<T>/ \mathrm{K}$ & $a$ & $B$ & $\frac{\Delta_{\mathrm{cr}}^{\mathrm{g}} H_{\mathrm{m}}^{\mathrm{o}}(<T>)}{\mathrm{kJ} \cdot \mathrm{mol}^{-1}}$ & $\frac{\Delta_{\mathrm{cr}}^{\mathrm{g}} H_{\mathrm{m}}^{\mathrm{o}}(T=298.15 \mathrm{~K})}{\mathrm{kJ} \cdot \mathrm{mol}^{-1}}$ \\
\hline A & 367.7 & $45.12 \pm 0.40$ & $16379 \pm 147$ & 136.18 & 139.7 \\
\hline B & 367.7 & $44.11 \pm 0.40$ & $16014 \pm 145$ & 133.15 & 136.6 \\
\hline $\mathrm{C}$ & 370.2 & $45.66 \pm 0.43$ & $16546 \pm 157$ & 137.57 & 141.1 \\
\hline $\mathrm{D}$ & 370.2 & $44.62 \pm 0.51$ & $16163 \pm 190$ & 134.39 & 138.0 \\
\hline $\mathrm{E}$ & 371.2 & $45.35 \pm 0.32$ & $16443 \pm 120$ & 136.72 & 140.4 \\
\hline
\end{tabular}

The derived standard molar enthalpies of formation, in both condensed and gaseous phases, at $T=298.15 \mathrm{~K}$, are summarized in table 7 .

TABLE 7

Derived standard $\left(p^{\circ}=0.1 \mathrm{MPa}\right)$ molar enthalpies of formation, at $T=298.15 \mathrm{~K}$

\begin{tabular}{lccc}
\hline Compound & $\Delta_{\mathrm{f}} H_{\mathrm{m}}^{\circ}(\mathrm{cr}) /\left(\mathrm{kJ} \cdot \mathrm{mol}^{-1}\right)$ & $\Delta_{\mathrm{cr}}^{\mathrm{g}} H_{\mathrm{m}}^{\circ} /\left(\mathrm{kJ} \cdot \mathrm{mol}^{-1}\right)$ & $\Delta_{\mathrm{f}} H_{\mathrm{m}}^{\circ}(\mathrm{g}) /\left(\mathrm{kJ} \cdot \mathrm{mol}^{-1}\right)$ \\
\hline DMANBF & $169.0 \pm 3.3$ & $134.2 \pm 3.4$ & $303.2 \pm 4.7$ \\
DEANBF & $132.8 \pm 4.9$ & $139.2 \pm 1.6$ & $272.0 \pm 5.2$ \\
\hline
\end{tabular}

\subsection{Calculated molecular structures}

The calculated molecular structures of the 4-N,N-dimethylamino-7-nitrobenzofurazan and 4- $N, N$-diethylamino-7-nitrobenzofurazan, optimized at the B3LYP/6$31 \mathrm{G}(\mathrm{d})$ level of theory (G3(MP2)//B3LYP calculations), are shown in figure 2, in which the selected bond distances and bond angles are included. 


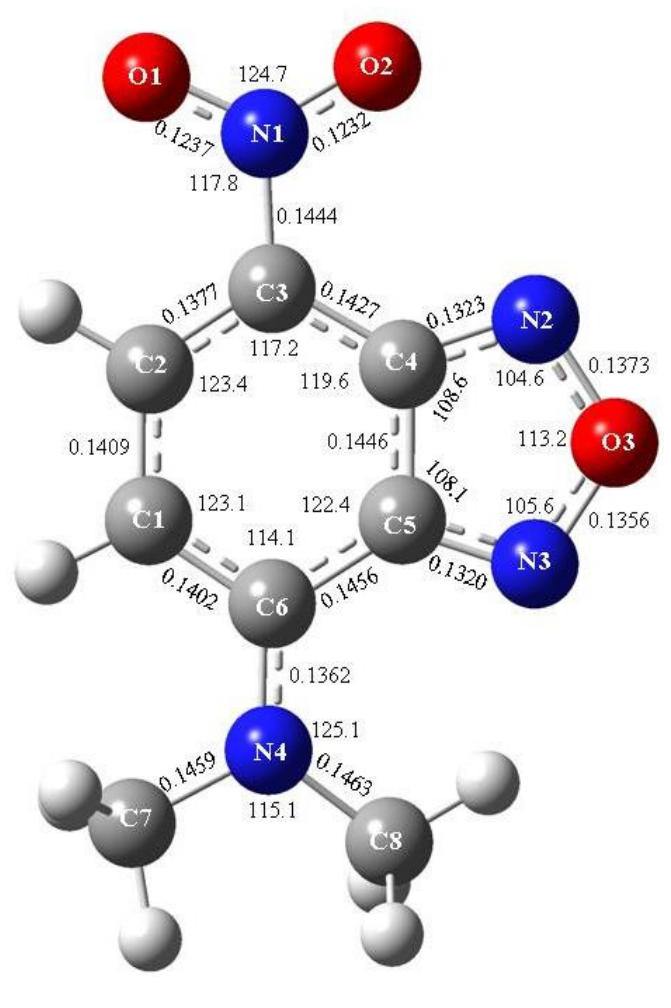

(a)

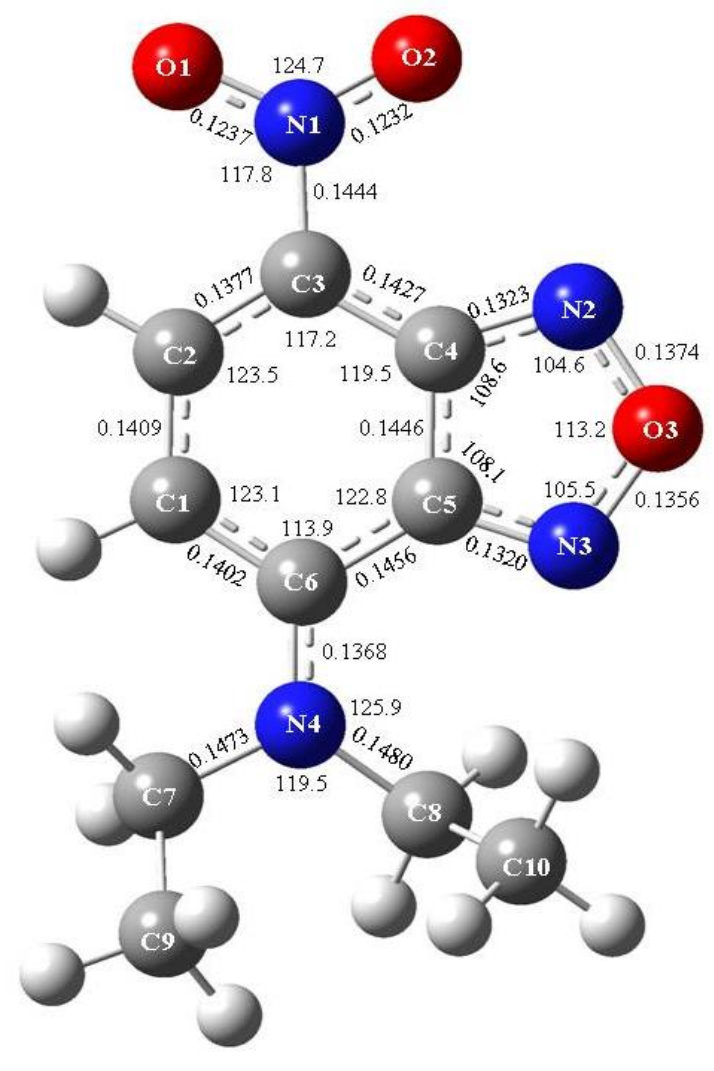

(b)

FIGURE 2. B3LYP/6-31G(d) optimized most stable configurations for the $4-N, N-$ dimethylamino-7-nitrobenzofurazan (a) and 4-N,N-diethylamino-7-nitrobenzofurazan (b). Selected bond lengths (nm) and bond angles (deg) are included.

In both molecules, the two fused rings are mainly planar due to their aromatic nature; the dihedral angle between the two rings is $0.2^{\circ}$ for the 4-N,N-dimethylamino-7nitrobenzofurazan and $0.5^{\circ}$ for the 4-N,N-diethylamino-7-nitrobenzofurazan. For the two heteropolycyclic compounds, the $-\mathrm{NO}_{2}$ group is almost coplanar with the core molecule, as seen by the dihedral angle $\mathrm{O}-\mathrm{N} 1-\mathrm{C} 3-\mathrm{C} 4,0.2^{\circ}$. Their calculated molecular geometry parameters compare very well between each other.

\subsection{Gas-phase experimental and computational enthalpies of formation}

The experimental derived standard molar enthalpies of formation, in the gaseous phase, $\Delta_{\mathrm{f}} H_{\mathrm{m}}^{\mathrm{o}}(\mathrm{g})$, at $T=298.15 \mathrm{~K}$, for the two studied compounds, are summarized in table 8 . In this table are also presented their computational gas-phase molar enthalpies of formation, estimated by combining the enthalpy of reactions (3)-(7), at $T=298.15 \mathrm{~K}$, 
computed at the G3(MP2)//B3LYP level, with the experimental enthalpies of formation of the auxiliary molecules used in those reactions.

\section{TABLE 8}

Experimental and G3(MP2)//B3LYP computed gas-phase enthalpies of formation, of the compounds studied, at $T$ $=298.15 \mathrm{~K}^{\mathrm{a}}$

\begin{tabular}{|c|c|c|c|c|c|c|}
\hline \multirow[b]{2}{*}{ Compound } & \multirow[b]{2}{*}{ Exp. } & \multicolumn{4}{|c|}{$\frac{\Delta_{\mathrm{f}} H_{\mathrm{m}}^{\mathrm{o}}(\mathrm{g})}{\mathrm{kJ} \cdot \mathrm{mol}^{-1}}$} & \\
\hline & & Eq. 3 & Eq. 4 & Eq. 5 & Eq. 6 & Eq. 7 \\
\hline DEANBF & $272.0 \pm 5.2$ & $263.4(8.6)$ & $265.0(7.0)$ & $266.9(5.1)$ & $268.0(4.0)$ & $268.1(3.9)$ \\
\hline
\end{tabular}

${ }^{a}$ Enthalpic differences between the experimental and computed values are given in parentheses.

From the data collected in table 8, we can observe, for 4- $N, N$-dimethylamino-7nitrobenzofurazan, that the estimated values are in good agreement with the experimental ones; the maximum deviation obtained from the experimental result is 4.5 $\mathrm{kJ} \cdot \mathrm{mol}^{-1}$, which is smaller than the uncertainty interval associated to the experimental value.

For the 4-N,N-diethylamino-7-nitrobenzofurazan, the comparison between the experimental $\Delta_{\mathrm{f}} H_{\mathrm{m}}^{\mathrm{o}}(\mathrm{g})$ and the calculated data shows a satisfactory agreement; the poor estimate is obtained when reaction (3) is considered, with an enthalpic deviation of 8.6 $\mathrm{kJ} \cdot \mathrm{mol}^{-1}$. However, when the estimates based on working reactions (6) and (7) are considered, the differences obtained are 4.0 and $3.9 \mathrm{~kJ} \cdot \mathrm{mol}^{-1}$, which are within the bounds of the experimental uncertainty.

The calculated values by the G3(MP2)//B3LYP method can have an average absolute deviation as large as $5.2 \mathrm{~kJ} \cdot \mathrm{mol}^{-1}$ [29]. Despite the average absolute deviation of the values calculated by the G3(MP2)//B3LYP, the data obtained by using the different working reactions (table 8) are among them, and with the experimental result, as well as within this possible deviation.

The computed G3(MP2)//B3LYP enthalpies for the compounds studied, auxiliary molecules used in the working reactions, as well as the literature values of $\Delta_{\mathrm{f}} H_{\mathrm{m}}^{\mathrm{o}}(\mathrm{g})$ for 
the auxiliary molecules are presented in table S3 in the supporting information; in figure $\mathrm{S} 1$ is given the estimated gas-phase enthalpy of formation, at $T=298.15 \mathrm{~K}$, for the $N, N$-diethyl-4-nitrobenzenamine. The results obtained were also analyzed in terms of enthalpic increments. The introduction of two $-\mathrm{CH}_{2}-$ groups in the $-\mathrm{N}\left(\mathrm{CH}_{3}\right)_{2}$ substituent of the 4-N,N-dimethylamino-7-nitrobenzofurazan, $\quad \mathrm{N}, \mathrm{N}$ dimethylbenzenamine and $N, N$-dimethyl-4-nitrobenzenamine is illustrated in the schemes of figure 3. From those schemes one can clearly see that the introduction of two ethylene groups in the $-\mathrm{N}\left(\mathrm{CH}_{3}\right)_{2}$ substituent of the three compounds referred above cause the same stabilizing effects, within the experimental uncertainties, showing that the presence of other groups in the ring do not induce additional enthalpic effects. The literature values of $\Delta_{\mathrm{f}} H_{\mathrm{m}}^{\mathrm{o}}(\mathrm{g})$ of the compounds presented in figure 3 and the respective references are in table $\mathrm{S} 3$, in the supporting information.<smiles>CN(C)c1ccc([N+](=O)[O-])c2nonc12</smiles>

$303.2 \pm 4.7$

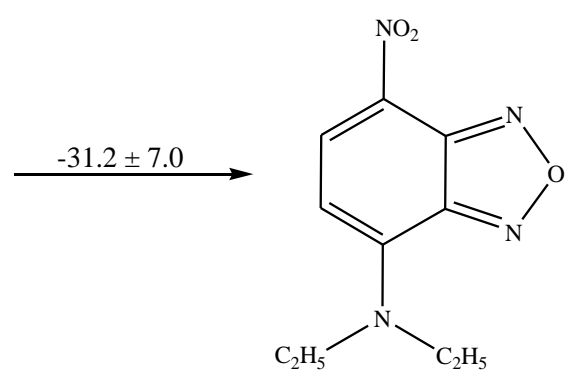

$272.0 \pm 5.2$

(a)<smiles>CN(C)c1ccccc1</smiles>

$100.5 \pm 3.4$

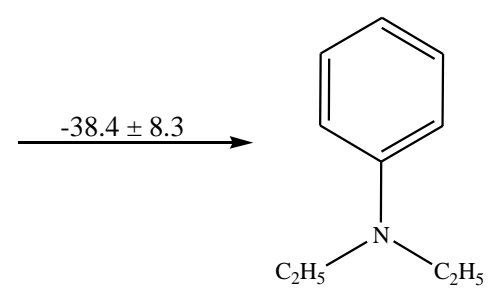

$62.1 \pm 7.6$

(b) 

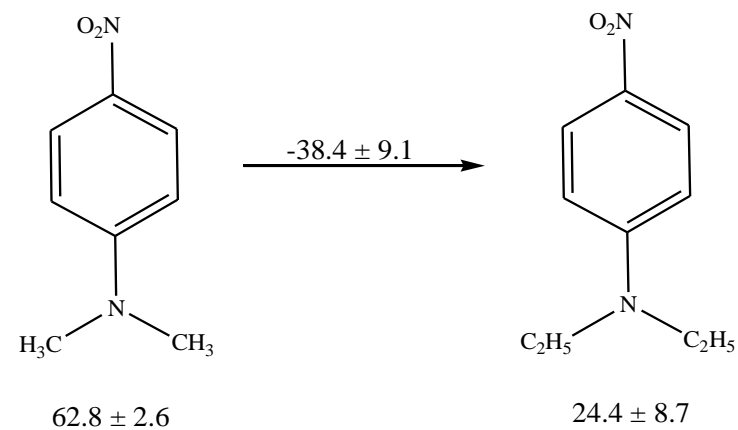

(c)

FIGURE 3. Enthalpic increments $\left(\mathrm{kJ} \cdot \mathrm{mol}^{-1}\right)$ of the introduction of two $-\mathrm{CH}_{2}-$ groups in the $-\mathrm{N}\left(\mathrm{CH}_{3}\right)_{2}$ substituent of the 4-N,N-dimethylamino-7-nitrobenzofurazan (a), N,N-dimethylbenzenamine (b) and N,N-dimethyl-4-nitrobenzenamine (c).

\section{Final Remarks}

In the present work, the standard molar enthalpies of formation, in the gaseous phase, for 4- $N, N$-dimethylamino-7-nitrobenzofurazan and 4- $N, N$-Diethylamino-7nitrobenzofurazan were determined by experimental (static bomb combustion calorimetry and Knudsen effusion technique) and computational methods (G3(MP2)//B3LYP approach). The experimental values obtained were, respectively, $(303.2 \pm 4.7)$ and $(272.0 \pm 5.2) \mathrm{kJ} \cdot \mathrm{mol}^{-1}$, and using different working reactions, a good agreement with the calculated data was achieved. At the B3LYP/6-31G(d) level of theory, the molecular structures of the compounds under study have been established and the structural parameters have been obtained. For both molecules, the two fused rings are mainly planar due to their aromatic nature. From an analysis of the experimental results obtained, in terms of enthalpic increments, it was shown that they correlate well between each other and with available literature values for structural related compounds. Finally, the values obtained in this work are an additional contribution for the systematic study of the dissociation enthalpy of terminal $\mathrm{N}-\mathrm{O}$ bonds in heterocyclic compounds. 


\section{References}

[1] W.E. Acree Jr, G. Pilcher, M.D.M.C. Ribeiro da Silva, J. Phys. Chem. Ref. Data 34 (2005) 553-572, and references cited therein.

[2] M.L.F. Viveiros, V.L.S. Freitas, N. Vale, J.R.B. Gomes, P. Gomes, M.D.M.C. Ribeiro da Silva, J. Phys. Org. Chem. 25 (2012) 420-426.

[3] J.R.B. Gomes, M.D.M.C. Ribeiro da Silva, M.A.V. Ribeiro da Silva, Chem. Phys. Lett. 429 (2006) 18-22.

[4] J.R.B. Gomes, E.A. Sousa, P. Gomes, N. Vale, J.M. Gonçalves, S. Pandey, W.E. Acree Jr., M.D.M.C. Ribeiro da Silva, J. Phys. Chem. B 111 (2007) 2075-2080.

[5] J.R.B. Gomes, E.A. Sousa, J.M. Gonçalves, L. Gales, A.M. Damas, P. Gomes, S. Pandey, W.E. Acree Jr., M.D.M.C. Ribeiro da Silva, J. Phys. Org. Chem. 20 (2007) 491-498.

[6] J.R.B. Gomes, M.A.A. Vieira, D.M. Stovall, W.E. Acree Jr., M.D.M.C. Ribeiro da Silva, Bull. Chem. Soc. Jpn, 80 (2007) 1770-1775.

[7] J.R.B. Gomes, A.R. Monteiro, B.B. Campos, P.Gomes, M.D.M.C. Ribeiro da Silva, J. Phys. Org. Chem. 22 (2009) 17-23.

[8] M.D.M.C. Ribeiro da Silva, M.A.A. Vieira, C. Givens, S. Keown, W.E. Acree Jr., Thermochim. Acta. 450 (2006) 67-70.

[9] M.D.M.C. Ribeiro da Silva, J.I.T.A. Cabral, C. Givens, S. Keown, W.E. Acree Jr., J. Therm. Anal. Calor. 92 (2008) 73-78.

[10] J.R.B. Gomes, E.A. Sousa, J.M. Gonçalves, M.J.S. Monte, P. Gomes, S. Pandey, et al., J. Phys. Chem. B. 109 (2005) 16188-16195.

[11] J.I.T.A. Cabral, R.A.R. Monteiro, M.A.A. Rocha, L.M.N.B.F. Santos, W.E. Acree Jr., M.D.M.C. Ribeiro da Silva, J. Therm. Anal. Calorim. 100 (2010) 431-439.

[12] A.F.L.O.M. Santos, A.R. Monteiro, J.M. Gonçalves, W.E. Acree Jr., M.D.M.C. Ribeiro da Silva, J. Chem. Thermodyn. 43 (2011) 1044-1049.

[13] M.D.M.C. Ribeiro da Silva, V.L.S. Freitas, M.A.A. Vieira, M.J. Sottomayor, W.E. Acree Jr., J. Chem. Thermodyn. 49 (2012) 146-153.

[14] M.S. Miranda, M.A.R. Matos, V.M.F. Morais, J.F. Liebman, J. Chem. Thermodyn. 50 (2012) 30-36.

[15] M.S. Miranda, M.A.R. Matos, V.M.F. Morais, J.F. Liebman, Struct. Chem. 23 (2012) 1241-1243.

[16] A.J. Boulton, P.B. Ghosh, A.R. Katritzky, J. Chem. Soc. (B) (1966) 1004-1011. 
[17] P.B. Ghosh, M.W. Whitehouse, J. Med. Chem. 11 (1968) 305-311.

[18] H.A. Gundry, D. Harrop, A.J. Head, G.B. Lewis, J. Chem. Thermodyn. 1 (1969) $321-332$

[19] M.D.M.C. Ribeiro da Silva, L.M.N.B.F. Santos, A.L.R. Silva, O. Fernandes, W.E. Acree Jr., J. Chem. Thermodyn. 35 (2003) 1093-1100.

[20] J. Coops, R.S. Jessup, K. vanNes, in: F.D. Rossini (Ed.), Experimental Thermochemistry, vol. 1, Interscience, New York, 1956 (Chapter 3).

[21] D.A. Wagman, W.H. Evans, V.B. Parker, R.H. Schumm, I. Halow, S.M. Bailey, K.L. Churney, R.L. Nuttall, The NBS Tables of Chemical Thermodynamics Properties, J. Phys. Chem. Ref. Data II (Suppl. 2) 1982.

[22] E.W. Washburn (1933) J Res Natl Bur Stand (US) 10:525-558

[23] Hubbard WN, Scott DW, Waddington G (1956) In: Rossini FD (ed) Experimental Thermochemistry, Vol. 1. Chapter 5. Interscience, New York

[24] P.M. Burkinshaw, C.T. Mortimer, J. Chem. Soc., Dalton Trans. (1984), 75-77.

[25] M.A.V. Ribeiro da Silva, J.M. Goncalves, J. Chem. Thermodyn. 30 (1998) 14651481

[26] M.A.V. Ribeiro da Silva, M.L.C.C.H. Ferrão, M.J.S. Monte, J.M. Goncalves. F. J. Jiye, J. Chem. Thermodyn. 31 (1999) 1067-1075.

[27] G. Sauerbrey, Z. Phys. 155 (1959) 206-222.

[28] M.J. Frisch, G.W. Trucks, H.B. Schlegel, G.E. Scuseria, M.A. Robb, J.R. Cheeseman, J.A. Montgomery Jr., T. Vreven, K.N. Kudin, J.C. Burant, J.M. Millam, S.S. Iyengar, J. Tomasi, V. Barone, B. Mennucci, M. Cossi, G. Scalmani, N. Rega, G.A. Petersson, H. Nakatsuji, M. Hada, M. Ehara, K. Toyota, R. Fukuda, J. Hasegawa, M. Ishida, T. Nakajima, Y. Honda, O. Kitao, H. Nakai, M. Klene, X. Li, J.E. Knox, H.P. Hratchian, J.B. Cross, V. Bakken, C. Adamo, J. Jaramillo, R. Gomperts, R.E. Stratmann, O. Yazyev, A.J. Austin, R. Cammi, C. Pomelli, J.W. Ochterski, P.Y. Ayala, K. Morokuma, G.A. Voth, P. Salvador, J.J. Dannenberg, V.G. Zakrzewski, S. Dapprich, A.D. Daniels, M.C. Strain, O. Farkas, D.K. Malick, A.D. Rabuck, K. Raghavachari, J.B. Foresman, J.V. Ortiz, Q. Cui, A.G. Baboul, S. Clifford, J. Cioslowski, B.B. Stefanov, G. Liu, A. Liashenko, P. Piskorz, I. Komaromi, R.L. Martin, D.J. Fox, T. Keith, M.A. Al-Laham, C.Y. Peng, A. Nanayakkara, M. Challacombe, P.M.W. Gill, B. Johnson, W. Chen, 
M.W. Wong, C. Gonzalez, J.A. Pople, Gaussian 03, Revision C.01, Gaussian, Inc., Wallingford CT, 2004.

[29] A.G. Baboul, L.A. Curtiss, P.C. Redfern, K. Raghavachari, J. Chem. Phys. 110 (1999) 7650-7657.

[30] F.D. Rossini, in: F.D. Rossini (Ed.), Experimental Thermochemistry, vol. 1, Interscience, New York, 1956 (Chapter 14).

[31] G. Olofson, in: S. Sunner, M. Månsson (Eds.), Combustion Calorimetry, vol. 1, Pergamon Press, Oxford, 1979 (Chapter 6).

[32] J.D. Cox, D.D. Wagman, V.A. Medvedev, CODATA Key Values for Thermodynamics, Hemisphere, New York, 1989. 